\title{
RHINOLOGY
}

\section{Are sinonasal dissection courses a valid instrument for endoscopic sinus surgeons? A report on 7-years of experience}

\author{
Corsi di chirurgia endoscopica dei seni paranasali: possono essere considerati un \\ valido strumento per il training chirurgico? Rapporto su 7 anni di esperienza
}

\author{
Fabio Pagella ${ }^{1,2}$, Enzo Emanuelli ${ }^{3}$, Marco Benazzo ${ }^{1,2}$, Alessandro Pusateri ${ }^{4}$, Sara Ugolini ${ }^{1,2}$, Michela Melegatti ${ }^{5}$, \\ Andrea Ciorba ${ }^{5}$, Stefano Pelucchi ${ }^{5}$ \\ ${ }^{1}$ ENT Department, I.R.C.C.S. Policlinico San Matteo-University of Pavia, Italy; ${ }^{2}$ ENT Department, University of Pavia, Italy; \\ ${ }^{3}$ Department of Neuroscience, Institute of Otorhinolaryngology, University Hospital of Padova, Italy; ${ }^{4}$ ENT and Skull-Base Surgery \\ Department, Department of Neurosciences, Ospedale Papa Giovanni XXIII, Bergamo, Italy; ${ }^{5}$ ENT \& Audiology Unit, Department of \\ Neuroscience and Rehabilitation, University Hospital of Ferrara, Italy
}

\section{SUMMARY}

Sinonasal dissection courses have been reported to be effective in teaching sinonasal anatomy to trainees, and in improving surgical skills for trained surgeons. Between 2013 and 2019, a standardised structured questionnaire was handed out to 130 participants of 8 sinonasal dissection courses. Each questionnaire included questions about the medical equipment the surgeons were fitted, and the problems encountered during the dissection. The majority of the participants, regardless of their experience and age, considered uncinectomy and anterior ethmoidectomy as the simplest parts of the dissection, whereas the most complicated step was the approach to the frontal sinus. All participants considered the dissection course as a useful way to improve their medical skills while performing an endoscopic surgery procedure, such as their anatomical knowledge, and confidence with instrumentation and the dissection. Sinonasal dissection courses can be considered to be useful for both trainees and trained surgeons. Improving anatomical knowledge can reduce the occurrence of complications, especially in endoscopic surgery.

KEY WORDS: endoscopic sinus surgery, functional endoscopic sinus surgery, fess, dissection course, surgery

\section{RIASSUNTO}

I corsi di chirurgia endoscopica naso-sinusale sono rivolti sia a giovani specialisti per il training chirurgico, sia a chirurghi più esperti per migliorare le abilità chirurgiche. Ad un totale di centotrenta (130) partecipanti, ad 8 corsi di dissezione in totale, tra il 2013 e il 2019, è stato somministrato un questionario strutturato standardizzato, comprendente domande sulla strumentazione ricevuta e problemi riscontrati durante la pratica di dissezione.L'uncinectomia e l'etmoidectomia anteriore sono state considerate le procedure più semplici del corso, dalla maggior parte dei partecipanti, mentre l'approccio al seno frontale, indipendentemente dall'esperienza e dall'età, è stato ritenuto il passaggio più complicato. Tutti i partecipanti hanno considerato il corso di dissezione come un mezzo utile per migliorare le loro conoscenze anatomiche, ed il grado di confidenza con la strumentazione e con la dissezione. I corsi di chirurgia endoscopica naso-sinusale sono stati ritenuti utili sia dai giovani specialisti, che dai chirurghi più esperti. Il miglioramento delle conoscenze anatomiche può ridurre efficacemente l'insorgenza di complicazioni indesiderate, in particolare per gli approcci endoscopici.

PAROLE CHIAVE: chirurgia endoscopica dei seni paranasali, corsi di dissezione, chirurgia
Received: February 24, 2020

Accepted: May 30, 2020

\section{Correspondence}

Andrea Ciorba

ENT \& Audiology Unit, Department of Neuroscience and Rehabilitation, University Hospital of Ferrara, via Aldo Moro 8, 44124 Ferrara, Italy Tel. +390532 239745

E-mail: andrea.ciorba@unife.it

Funding

None.

Conflict of interest

The Authors declare no conflict of interest.

How to cite this article: Pagella F, Emanuelli E, Benazzo M, et al. Are sinonasal dissection courses a valid instrument for endoscopic sinus surgeons? A report on 7-years of experience. Acta Otorhinolaryngol Ital 2020;40:415-420. https:// doi.org/10.14639/0392-100X-N0705

(C) Società Italiana di Otorinolaringoiatria e Chirurgia Cervico-Facciale

\section{(c) (i) $(9)$}

This is an open access article distributed in accordance with the CC-BY-NC-ND (Creative Commons Attribution-NonCommercial-NoDerivatives 4.0 International) license. The article can be used by giving appropriate credit and mentioning the license, but only for non-commercial purposes and only in the original version. For further information: https:// creativecommons.org/licenses/by-nc-nd/4.0/deed.en 


\section{Introduction}

Sinonasal dissection courses are nowadays an established and fundamental part of the training of ENT surgeons, especially for those who are approaching Endoscopic Sinus Surgery (ESS). These courses are important because of the lack of anatomic facilities or valid simulation tools, and because of the difficult access to specimens related to a number of issues (such as cultural, religious, legal restrictions) ${ }^{1,2}$. Sinonasal dissection courses are able to allow: (i) understanding of the surgical anatomy; (ii) perception of the difficulties and complications that are likely to be encountered by surgeons, which must be handled promptly; (iii) improvement of confidence with the endoscopes ${ }^{3}$. Dissection courses usually begin with a theoretical explanation of the surgical anatomy of paranasal sinuses and surrounding structures, following by hands-on training on cadavers. Dissection courses have been shown to be effective in teaching sinonasal anatomy to trainees, as well as in improving surgical skills of trained surgeons and reducing the occurrence of complications during an ESS procedure ${ }^{4-6}$. Nowadays, the reported risk of complications during an ESS procedure ranges from 4 to $17 \%{ }^{7}$. This percentage is composed of $5 \%$ minor complications, and $0.5-1 \%$ of major complications ${ }^{8}$, including orbit injures, I and II cranial nerves, vascular structures (i.e. internal carotid artery, ethmoidal artery) ${ }^{9}$.

The aim of this paper is to describe the strengths and weaknesses of sinonasal dissection courses during surgical training for sinonasal surgery, through the evaluation of questionnaire responses given to participants.

\section{Materials and methods}

One hundred and thirty participants attended a total of 8 sinonasal dissection courses between 2013 and 2019 in two different Italian cities (Arezzo and Verona), and all received a standardised structured questionnaire. Each questionnaire included questions about the medical instrumentation the participants were fitted, and the problems encountered during the dissection or dissection practice.

Each dissection course had a duration of three days; each day included an introductive theoretical part and hands-on training on cadavers.

The introductive theoretical part addressed the following topics: rhinosinusal surgical and radiological anatomy of the anterior and posterior compartments; anatomy of the lacrimal pathway and orbit, anatomy of the sellar region, pterygopalatine fossa and the cranial base as well as the vascular anatomy; risks of endoscopic sinus surgery (ESS) and extended endoscopic endonasal approaches.

Each dissection step was displayed in a short video of the same procedure. The surgical steps included uncinectomy and maxillary antrostomy, access to the maxillary sinus via canine fossa, identification of the ethmoid infundibulum, the frontal recess and the natural frontal sinus ostium, removal of the ethmoidalis bulla, identification of the basal lamella and the superior turbinate, and opening of the sphenoid ostium.

The participants then performed hands-on dissections: anterior and posterior ethmoidectomy; sphenoidotomy (paraseptal and transethmoid pathway); orbital decompression; sphenopalatine artery identification. The participants also performed endoscopic medial maxillectomy, access to the sellar and parasellar region and repair techniques for cranial base defects.

A structured questionnaire was handed out to the participants at the end of each course, and they were asked to fill it out anonymously (see also Fig. 1 for the questionnaire).

\section{Statistical analysis}

Data were analysed using SPSS Statistics 17.0 (SPSS Inc., Chicago, IL, USA). Levels of significance were: $\mathrm{p}<0.1^{*}$; $\mathrm{p}<0.05^{* *}$; n.s.: not statistically significant.

\section{Results}

A total of 130 structured questionnaires were submitted to the participants. The average age of participants was 38 years (range 27-62 years), and on average they had been practicing ENT for 8.8 years (range 0-35 years). Since the questionnaire was performed anonymously, we could not retrieve information about the $\mathrm{M} / \mathrm{F}$ ratio.

$18 \%$ of participants declared problems with the instrumentation, mostly due to the lack of specific instruments or because of malfunctioning instruments.

$15.5 \%$ of participants declared problems with anatomy, mainly due to a scarce confidence with anatomy and/or little experience; only a few participants had problems with the dissection, due to lack of experience, difficulty of the surgical task (such as skull base approach), or poor manual skills.

$11.7 \%$ had problems during the dissection (either due to inexperience or due to performing difficult dissection steps, such as the skull base approach; either due to scarce confidence with the anatomy or poor manual ability with instruments).

The results concerning specific dissection steps were also analysed:

- $2.3 \%$ declared problems with uncinectomy;

- $2.3 \%$ declared problems with anterior ethmoidectomy;

- $27.9 \%$ declared problems with posterior ethmoidectomy (the participants complained problems such as the pres- 


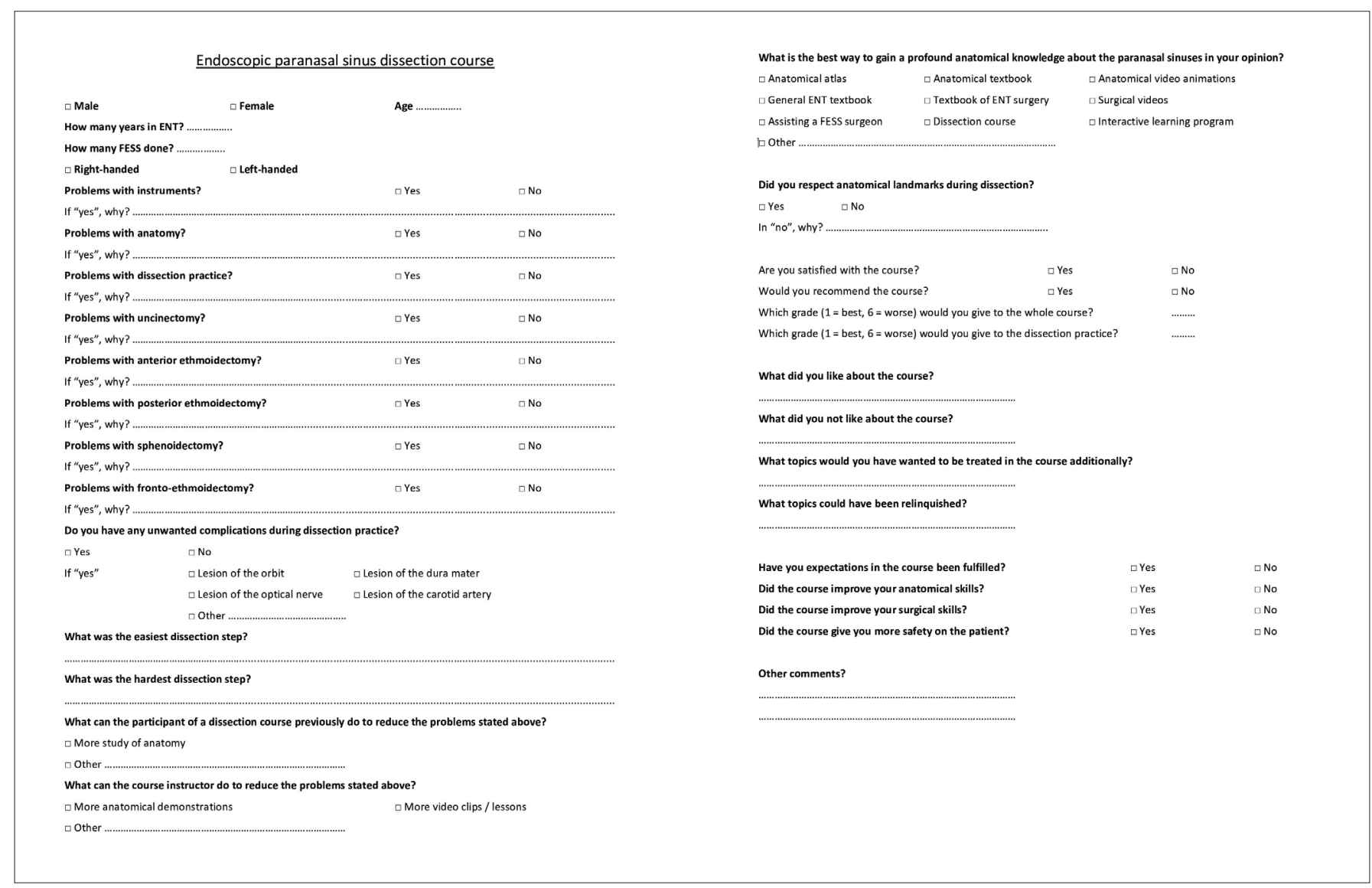

Figure. 1. Structured questionnaire used during the dissection courses.

ence of complex anatomy; two surgeons encountered problems due to lack of landmarks; other surgeons declared difficulties due to lack of knowledge of anatomy and inexperience in dissection; other participants declared difficulties due to the presence of anatomical variants, such as excessive pneumatisation);

- $19.38 \%$ declared problems with sphenoidotomy (for the same reasons mentioned above);

- $29.46 \%$ declared problems with the access to the fronto-ethmoid (during this dissection step difficulties were referred to the complex anatomy of the frontal sinus, lack of landmarks, wide anatomical variability of this district and also to the troubles in using angled optics).

Most of the surgeons identified and spared anatomical landmarks; however, several complications occurred during the dissection; in particular, $31.5 \%$ of the participants encountered unwanted complications during the dissection, such as orbit lesions (14 participants), meningeal lesions ( 8 participants), vascular lesions, rhinoliquoral fistula (4 participants) and optic nerve lesions (4 participants).
The simplest part of the dissection was reported to be uncinectomy $(76.4 \%)$, followed by antrostomy $(11.8 \%)$, anterior ethmoidectomy $(9.4 \%)$, sphenoidotomy $(1.6 \%)$ and frontal sinus access $(0.8 \%)$.

The most difficult part of the dissection was reported to be access to the fronto-ethmoid recess $(37.8 \%)$, followed by posterior ethmoidectomy (22.7\%), sphenoidotomy (15.1\%), orbital decompression (9.2\%) and DCR (3.4\%).

The participants declared that the best way to acquire surgical anatomical knowledge (multiple choice question) was: participation (82.4\%); assisting in a surgery performed by a well-trained ENT surgeon (36.8\%); studying surgical videos (36\%); studying anatomical videos $(31.2 \%)$; studying anatomic atlases (33.6\%); studying ENT books (14.4\%); studying anatomy texts (11.2\%); using interactive programmes (8.8\%); studying other ENT books (8\%). All participants $(100 \%)$ were eventually satisfied with the course and would all recommend to other colleagues to take part in it.

The overall course evaluation obtained an average score of 1.788 (the range was from 1 , maximum score - to 6 , mini- 
mum score). The overall dissection evaluation obtained an average score of 1.915 (the range was from 1, maximum score - to 6, minimum score).

We then divided the 130 participants into two groups for statistical analysis, setting a cut-off at the age of 40 . On average, those aged $\geq 40$ were already more experienced in nasal surgery training (see below), according to the participants' declarations within the questionnaire. We therefore tested the hypothesis that the experience is a determining variable for the surgeon's practice.

Fifteen participants did not specify their age in the questionnaire and were excluded. Hence, group 1 consisted of 77 participants $(66.95 \%)$, aged $<40$, with an average ENT practice period of 4.29 years; group 2 consisted of 38 participants (33.05\%), aged $\geq 40$, with an average ENT practice period of 17.29 years.

Participants who declared problems with using the instruments were $17.1 \%$ of group 1 and $15.8 \%$ of group 2 $(\mathrm{p}=0.86)$. Participants who declared problems with anato- my were $15.6 \%$ of group 1 and $15.8 \%$ of group $2(p=0.87)$. Participants who declared dissection problems were $11.7 \%$ of group 1, and $13.5 \%$ of group 2 (n.s., as $\mathrm{p}=0.82$ ) (Tab. I). Concerning problems encountered while performing different steps (Tab. II):

- uncinectomy and anterior ethmoidectomy: $2.6 \%$ of group 1 and $2.7 \%$ of group 2 declared problems for uncinectomy; $2.6 \%$ of both groups for the anterior ethmoidectomy; $\mathrm{p}=0.97$ and $\mathrm{p}=0.99$, respectively;

- posterior ethmoidectomy: $31.2 \%$ of group 1 declared problems vs $26.3 \%$ of group $2(\mathrm{p}=0.59)$;

- sphenoidotomy: $34.2 \%$ of those of group 2 declared difficulties in this step, compared to $13 \%$ of those of group $1, \mathrm{p}=0.007^{* *}$;

- fronto-ethmoidectomy: $27.3 \%$ of group 2 declared difficulties in performing the dissection, compared to $39.5 \%$ of group 1 (n.s, p = 0.18).

In the end, there are no significant differences between the two groups, either related to the total number of unwanted

Table I. Comparison between the overall problems referred by the studied groups.

\begin{tabular}{lcc} 
Problems with the instruments & Yes n./tot (\%) & No n./tot \\
$<40$ y.o. & $13 / 76(17.1 \%)$ & $63 / 76$ \\
$\geq 40$ y.o. & $6 / 38(15.8 \%)$ & $32 / 38$ \\
\hline Problems with the anatomy & & \\
$<40$ y.o. & $12 / 77(15.6 \%)$ & $65 / 77$ \\
$\geq 40$ y.o. & $6 / 38(15.8 \%)$ & $32 / 38$ \\
\hline Problems with dissection & & $68 / 77$ \\
$<40$ y.o. & $9 / 77(11.7 \%)$ & $33 / 37$ \\
$\geq 40$ y.o. & $5 / 37(13.5 \%)$ & \\
\hline
\end{tabular}

Table II. Comparison between the complications declared by the studied groups.

\begin{tabular}{lcc} 
Problems with uncinectomy & Yes n./tot (\%) & No n./tot \\
$<40$ y.o. & $2 / 77(2.6 \%)$ & $75 / 77$ \\
$\geq 40$ y.o. & $1 / 37(2.7 \%)$ & $36 / 37$ \\
\hline Problems with ant. ethmoidectomy & & \\
$<40$ y.o. & $2 / 77(2.6 \%)$ & $75 / 77$ \\
$\geq 40$ y.o. & $1 / 38(2.6 \%)$ & $37 / 38$ \\
\hline Problems with post. ethmoidectomy & & $53 / 77$ \\
$<40$ y.o. & $24 / 77(31.2 \%)$ & $28 / 38$ \\
$\geq 40$ y.o. & $10 / 38(26.3 \%)$ & \\
Problems with sphenoidotomy & & $67 / 77$ \\
$<40$ y.o. & $10 / 77(13 \%)$ & $25 / 38$ \\
$\geq 40$ y.o. & $13 / 38(34.2 \%)$ & \\
Problems with frontal sinus & & $56 / 77$ \\
$<40$ y.o. & $21 / 77(27.3 \%)$ & $23 / 38$ \\
$\geq 40$ y.o. & $15 / 38(39.5 \%)$ & \\
\hline
\end{tabular}


complications ( $\mathrm{p}=0.92$ ), or to the single type of complications reported.

The simplest part of the dissection was uncinectomy for $87.7 \%$ of those of group 1, and for $72.2 \%$ of those of group 2 ; uncinectomy was also reported to be an easier step by the younger surgeons, compared to the experienced surgeons. Other dissection steps, such as antrostomy, anterior ethmoidectomy, sphenoidotomy, did not show significant differences between the two groups. Lastly, $1.4 \%$ of participants in group 1 considered access to the frontal sinus as the simplest step, which was not mentioned by any surgeon in group 2 .

The opposite question was asked to participants: "What was the most difficult part of the dissection?", $30 \%$ of those of group 1 considered the posterior ethmoid as the most complex procedure, against $14.3 \%$ of the second group $\left(p=0.09^{*}\right)$. The sphenoid was voted as the most complex procedure by the $8.6 \%$ of those of group 1 and by the $22.8 \%$ of those of group $2\left(\mathrm{p}=0.06^{*}\right)$.

In the end, $89.6 \%$ of those of group 1 declared the dissection course to be the best way to acquire the surgical anatomical knowledge, compared to the $71.4 \%$ of those in group $2\left(\mathrm{p}=0.02^{*}\right)$.

\section{Discussion}

ESS is now widely used by ENT specialists around the world to treat inflammatory conditions, malformations and neoplastic diseases of the nasal cavities and paranasal sinuses. The first steps of ESS are linked to the names of Messerklinger, Stammberger and Storz ${ }^{1}$; they allowed replacing the previous open technique with considerable advantages from prognostic, surgical and therapeutic points of view ${ }^{2-5}$.

ESS represents the best surgical technique for the treatment of nasal cavities and paranasal sinus diseases, which is among the most highly complex and variable anatomical districts of the human body. One limitation is represented by the two-dimensional vision of the optics, which does not allow the depth perception. Anatomical variability of sinuses and potential severe complications (vascular, cerebral as well as neurological) related to this surgery should be however taken in account when dealing with ESS. For these reasons, knowledge of the anatomy of this district is a fundamental prerequisite for safely dealing with the technique.

Sinonasal dissection courses are nowadays a mandatory part of the ENT surgeon training, and are even attended by trained surgeons, in order to improve skills in procedures on anatomic variants ${ }^{1,2}$. Based on other experiences (Braun et al. ${ }^{10}$ ), the participants were divided into two groups according to their age and experience (as declared on the questionnaires), in order to evaluate the problems arising at different levels of surgical practice, and along the learning curve.
Through the evaluation of the data from our study, those in group 1 (younger surgeons) mainly reported difficulties due to the scarce manual ability and because of the presence of an anatomical variant (i.e. excessive pneumatisation).

The analysis highlighted that most of the participants at our sinonasal courses were $<40$ years of age $(66.95 \%)$. It is possible that young surgeons approaching ESS are attracted by many reasons such as: (i) the possibility of learning sinonasal surgical anatomy safely; (ii) the opportunity of improving their confidence with endoscopes, and particularly with angled optics. In many hospitals' ordinary routines, young surgeons have usually a lower chance of performing sinonasal surgery as first operator than experienced surgeons; attending dissection courses can therefore improve their skills in a safe way.

It is interesting to notice that, according to the results of the study by Braun and Betz ${ }^{10}$, our study also showed that: uncinectomy and anterior ethmoidectomy represented the simplest parts of the dissection, regardless of experience and age, whereas the most complicated step was considered to be the approach to the frontal sinus for all the groups. Concerning sphenoidotomy, it is possible that the differences among the groups are caused by different approaches to this step: young surgeons just performed the minimal/ essential approach to the sphenoid sinus, whereas trained surgeons performed a complete and functional opening, which exposes to greater risks and complications.

In the end, no differences were observed between the two groups, neither concerning the total occurrence rate of unwanted complications, nor considering the types of unwanted complications that can occur during the dissection. Despite this, just $31.5 \%$ of all participants experienced a minor or major complication, and thus it is possible to state that constant practice and exercise are efficient ways to improve ones expertise, reducing the occurrence of complications for the surgeon approaching ESS surgery and for trained surgeons as well.

There is no commercially available simulator for ESS that is particularly successful in simulating the anatomy with force feed-back so far, as opposed to other areas; a number have been described, but none are available ${ }^{4,12,13}$. Participating in a cadaver course is nonetheless a must in training young surgeons, especially to improve manual abilities in a safe way ${ }^{4,12,13}$, despite difficult access to specimens related to a number of issues (such as cultural, religious, legal restrictions) $)^{4,12-14}$.

\section{Conclusions}

In conclusion, the authors believe that hands-on courses are beneficial and satisfactory for both younger and trained surgeons, and all the participants were satisfied with the 
course and would all suggest to other colleagues to participate in future courses. The authors are also willing to improve the questionnaire for future courses, and will try to evaluate which skill is considered to be the most improved by each participant during the course.

\section{References}

1 Tajudeen BA, Kennedy DW. Thirty years of endoscopic sinus surgery: what have we learned? World J Otorhinolaryngol Head Neck Surg 2017;21:115-21. https://doi.org/10.1016/j.wjorl.2016.12.001

2 Ahmed OH, Marcus S, Lebowitz RA, et al. Evolution in visualization for sinus and skull base surgery. Otolaryngol Clin North Am 2017;50:505-19. https://doi.org/10.1016/j.otc.2017.01.003

3 Ogino-Nishimura E, Nakagawa T, Sakamoto T, et al. Efficacy of three-dimensional endoscopy in endonasal surgery. Auris Nasus Larynx 2015;42:203-7. https://doi.org/10.1016/j.anl.2014.10.004

4 Zuckerman JD, Wise SK, Rogers GA, et al. The utility of cadaver dissection in endoscopic sinus surgery training courses. Am J Rhinol Allergy 2009;23:218-24. https://doi.org/10.2500/ajra.2009.23.3297

5 Phillips JS, Vowler SL, Salam MA. Is training in endoscopic sinus surgery detrimental to patient outcome? J Surg Educ 2007;64:278-81. https://doi.org/10.1016/j.jsurg.2007.07.003

6 McMains KC. Safety in endoscopic sinus surgery. Curr Opin Otolaryngol Head Neck Surg 2008;16:247-51. https://doi.org/10.1097/ MOO.0b013e3282fdccad
7 Ulualp SO. Complications of endoscopic sinus surgery: appropriate management of complications. Curr Opin Otolaryngol Head Neck Surg 2008;16:252-9. https://doi.org/10.1097/MOO.0b013e3282fdc3b2.

8 Solyar A, Cuellar H, Sadoughi B, et al. Endoscopic sinus surgery simulator as a teaching tool for anatomy education. Am J Surg 2008;196:120-4. https://doi.org/10.1016/j.amjsurg.2007.06.026

9 Ramakrishnan VR. Ergonomics in endoscopic sinus surgery. Curr Opin Otolaryngol Head Neck Surg 2019;27:25-8. https://doi. org/10.1097/MOO.0000000000000504

10 Braun T, Betz CS, Ledderose GJ, et al. Endoscopic sinus surgery training courses: benefit and problems - a multicentre evaluation to systematically improve surgical training. Rhinology 2012;50: 246-54. https://doi.org/10.4193/Rhino11.266

11 Ossowski KL, Rhee DC, Rubinstein EN, et al. Efficacy of sinonasal simulator in teaching endoscopic nasal skills. Laryngoscope 2008;118:1482-5. https://doi.org/10.1097/MLG.0b013e3181772d4f

12 Laeeq K, Lin SY, Varela DA, et al. Achievement of competency in endoscopic sinus surgery of otolaryngology residents. Laryngoscope 2013;123:2932-4. https://doi.org/10.1002/lary.23509

13 Bakker NH, Fokkens WJ, Grimbergen CA. Investigation of training needs for functional endoscopic sinus surgery (FESS). Rhinology 2005;43:104-8.

14 Alicandri-Ciufelli M, Marchioni D, Pavesi G, et al. Acquisition of surgical skills for endoscopic ear and lateral skull base surgery: a staged training programme. Acta Otorhinolaryngol Ital 2018;38:1519. https://doi.org/10.14639/0392-100X-1878 